\title{
Longitudinal changes of self-perceived manual ability the first year after stroke: a cohort study
}

\author{
Elisabeth Ekstrand ${ }^{1,2}$, Katharina S. Sunnerhagen ${ }^{3}$, Hanna C. Persson ${ }^{3}$, Åsa Lundgren-Nilsson ${ }^{3}$ and \\ Margit Alt Murphy ${ }^{3^{*}}$ (D)
}

\begin{abstract}
Background: Recovery patterns of motor function and activity capacity of the upper extremity after stroke have been described, but less is known about longitudinal changes of perceived manual activity performance. The aim of this study was to investigate longitudinal changes of self-perceived manual ability at several timepoints from onset until 12 months post-stroke in a cohort of consecutively recruited individuals with mild, moderate and severe stroke.

Methods: The study included 106 participants from a non-selected cohort with first-ever mild, moderate or severe stroke and impaired upper extremity function (Stroke Arm Longitudinal Study at the University of Gothenburg, SALGOT). Self-perceived manual ability was assessed with the ABILHAND Questionnaire at 3 and 10 days, 4 weeks, 3, 6 and 12 months after stroke. Longitudinal change was assessed by linear mixed models (fixed and random effects) and adjusted models were built by adding effects of cofactors age, gender, stroke severity, living condition and affected hand.

Results: Self-perceived manual ability increased over time the first year after stroke for the total group and the subgroups. The final adjusted model for the total group included fix-effects of time (expected mean change 0.24 logits per month) adjusted by age ( -0.06 per year) and stroke severity ( -0.19 per NIHSS-score). In addition to significant effect of time, the adjusted models for moderate stroke subgroup included fixed effect of age, and for mild and severe subgroups there was an interaction effect between time and age. Further analyses between timepoints showed that no significant change of self-perceived manual ability was detected beyond 3 months poststroke.

Conclusions: Self-perceived manual ability increased over time the first year after stroke, and this change was to some degree modulated by age and stroke severity at onset. Most of the improvements occurred early, predominantly within the first three months after stroke.
\end{abstract}

Keywords: Activities of daily living, Longitudinal study, Recovery, Stroke, Self report, Upper extremity

\footnotetext{
* Correspondence: margit.alt-murphy@neuro.gu.se

${ }^{3}$ Department of Clinical Neuroscience, Rehabilitation Medicine, Institute of

Neuroscience and Physiology, Sahlgrenska Academy, University of

Gothenburg, Per Dubbsgatan 14, 3tr, S-413 45 Göteborg, Sweden

Full list of author information is available at the end of the article
}

(C) The Author(s). 2020 Open Access This article is licensed under a Creative Commons Attribution 4.0 International License, which permits use, sharing, adaptation, distribution and reproduction in any medium or format, as long as you give appropriate credit to the original author(s) and the source, provide a link to the Creative Commons licence, and indicate if changes were made. The images or other third party material in this article are included in the article's Creative Commons licence, unless indicated otherwise in a credit line to the material. If material is not included in the article's Creative Commons licence and your intended use is not permitted by statutory regulation or exceeds the permitted use, you will need to obtain permission directly from the copyright holder. To view a copy of this licence, visit http://creativecommons.org/licenses/by/4.0/ The Creative Commons Public Domain Dedication waiver (http://creativecommons.org/publicdomain/zero/1.0/) applies to the data made available in this article, unless otherwise stated in a credit line to the data. 


\section{Background}

After stroke, impairments of the upper extremity are common and affect approximately $50-70 \%$ of the stroke survivors in the acute stage $[1,2]$ and $40 \%$ in the chronic phase $[1,3]$. A remaining upper extremity impairment may negatively impact daily life and limit the ability to perform manual activities necessary for independent living [4]. To regain manual ability is therefore an important goal in stroke rehabilitation [5].

To follow recovery and effects of interventions after stroke different aspects of the ICF (International Classification of Functioning, Disability and Health) [4] needs to be considered. There are recommendations of core measures after stroke [6] to be used such as the National Institutes of Health Stroke Scale (NIHSS) [7] to measure stroke severity, the Fugl-Meyer Assessment for Upper Extremity (FMA-UE) [8] to measure upper extremity impairments and Action Research Arm Test (ARAT) [9] to measure activity capacity limitations. As recovery of functions do not automatically lead to improvements in performing upper extremity activities in real life [10] measures of activity performance are also essential to include. Self-reported activity measures, such as the ABILHAND Questionnaire [11], provide important information of the performance of activities in daily life after stroke that is relevant from the perspective of the person [12].

After a stroke, the major part of recovery of the upper extremity usually takes place within the first few months but improvements can continue for a longer time [10]. Regained body functions are mainly due to spontaneous neurobiological recovery [13] while improvement of activities depends on complex interaction between upper extremity functions and adaptive and compensatory behaviours [14]. Recovery has been found to differ depending on stroke severity, being more predictable for individuals with mild and moderate stroke compared to severe strokes [15]. Assessments of upper extremity motor function and activity capacity has been shown to be equally effective to measure recovery in the acute and early subacute stage post-stroke [16], but less is known about longitudinal changes of perceived manual activity performance. In previous studies increased self-reported amount of use of the upper extremity has been reported between discharge from inpatient rehabilitation and 12 months after stroke [17]. Increased perceived manual ability (ABILHAND logits) has also been demonstrated in a longitudinal study with several follow-up timepoints in the rehabilitation and post-rehabilitation phase [18]. Both studies included, however, participants at average of 1 month after stroke onset and used followup time-points that varied according to the participant's admission and/or discharge times $[17,18]$. Thus, studies are lacking that investigate longitudinal changes of perceived activity performance by repeated measurements in well-defined time-points from stroke onset well into the chronic phase. Increased understanding about perceived manual ability after stroke would facilitate efficient goal setting and individualised rehabilitation interventions with appropriate timing after stroke.

The aim of this study was to investigate longitudinal changes of self-perceived manual ability at several timepoints from onset until 12 months post-stroke in a cohort of consecutively recruited individuals with mild, moderate and severe stroke.

\section{Methods \\ Participants}

This longitudinal study is a part of the Stroke Arm Longitudinal Study at the University of Gothenburg (SALGOT). The SALGOT-study comprised a non-selected cohort of 117 adults with first-ever stroke admitted to the largest stroke unit at Sahlgrenska University Hospital in Sweden during a 18 month period between 2009 to 2010 [19]. Inclusion criteria were i) ischemic or haemorrhagic stroke (confirmed by clinical neuroimaging); ii) upper extremity disability at 3 days after stroke onset (Action Research Arm Test, ARAT < 57); iii) resident in Gothenburg urban area; iv) 18 years or older; v) Swedish speaking; vi) no other upper extremity condition that limited the functional use of arm and hand; vii) no severe multi-impairment, diminished physical condition or short life expectancy due to other chronic or terminal illness prior to stroke. The current study included data from 106 participants that responded to the ABILHAND Questionnaire (self-perceived manual ability) at 3 and 10 days, 4 weeks, 3, 6 or 12 months after stroke [19] (see Fig. 1). All participants received individually adjusted task-specific rehabilitation (physiotherapy and/or occupational therapy) from stroke onset (first day at stroke unit). Continued rehabilitation (in-patient and/or outpatient) was given based on the individuals' needs according to the Swedish national guidelines [20].

\section{Assessment}

Stroke severity at admission was measured by the NIHSS [7]. The total score ranges from 0 (no deficit) to 42 (severe deficit) [21]. Based on the NIHSS score the participants were allocated to one of three subgroups; mild (NIHSS score $<5$ ), moderate (NIHSS score 5 to 14) and severe stroke (NIHSS score >14) [7]. Barrow Neurological Institute (BNI) [22] pre-screening, with a maximum score of 9 points, was performed to assess level of alertness, basal communication and co-operation in order to verify that the persons could adequately take part in assessments and respond to self-reported measures. Upper extremity motor and sensory function 3 days post stroke were assessed by the FMA-UE [8] and 


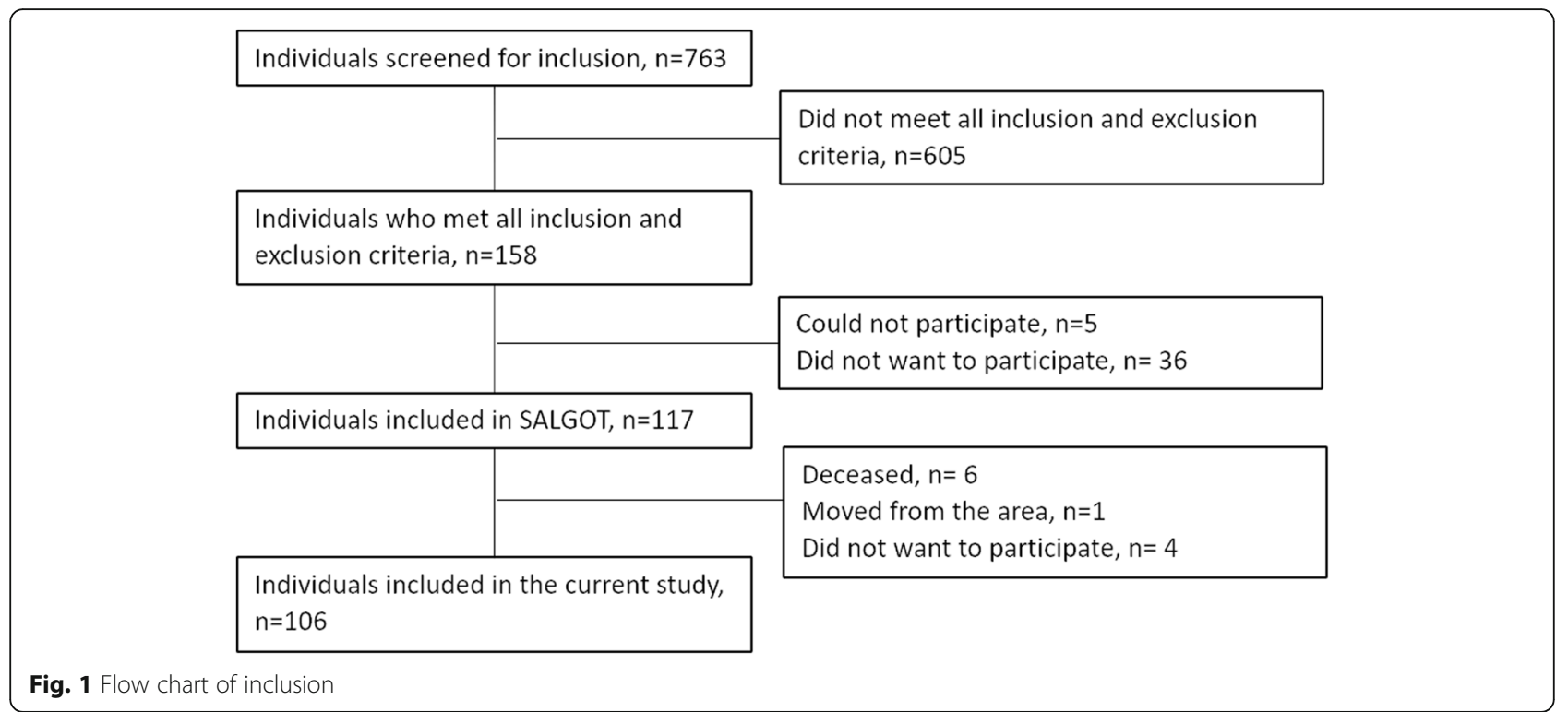

grip strength, calculated as percentage of reference values adjusted for age, sex and hand dominance, by the Jamar dynamometer (Sammons Preston, Chicago) [23, 24].

Self-perceived manual ability was assessed by the ABILHAND Questionnaire [11], Table 1. The ABILHAND is validated, has acceptable test-retest reliability and is recommended for assessment of upper extremity activity performance for individuals with stroke $[11,25,26]$. It includes 23 common bimanual tasks that are rated during an interview as impossible, difficult or easy. By the Rasch measurement model the score is converted into an interval scale in logits (i.e. log odds units) distributed around zero which indicates the centre of the scale [27]. A higher positive logit score indicates better self-perceived manual ability. If a participant could not answer to the questions of the ABILHAND, the test was recorded as missing.

\section{Statistics}

Descriptive statistics of frequencies, means, standard deviations (SD), medians and interquartile ranges were used for clinical and demographic characteristics.

Longitudinal change of self-perceived manual ability was assessed by linear mixed models. Model assumptions were checked by means of residual analysis. Linear mixed models take into account missing values and that observations are not independent (several measurements per individual). The models were tested for different levels of fixed and random effects in order to see if more variance could be explained by separate effects. Adjusted models were built by adding effects of the cofactors age, gender, stroke severity (NIHSS-score), living condition (living alone) and affected hand (dominant). Interaction effects between cofactors were also analysed. The

\section{Table 1 The ABILHAND Questionnaire}

\begin{tabular}{ll}
\hline Items & \\
\hline 1 & Hammering a nail \\
2 & Threading a needle \\
3 & Peeling potatoes \\
4 & Cutting one's nails \\
5 & Wrapping up gifts \\
6 & Cutting meat \\
7 & Filing one's nails \\
8 & Peeling onions \\
9 & Shelling hazel nuts \\
10 & Opening a screw-topped jar \\
11 & Fastening the zipper of a jacket \\
12 & Tearing open a pack of chips \\
13 & Buttoning up a shirt \\
14 & Sharpening a pencil \\
15 & Taking the cap off a bottle \\
16 & Spreading butter on a slice of bread \\
17 & Fastening a snap (jacket, bag) \\
18 & Buttoning up trousers \\
19 & Opening mail \\
20 & Pulling up the zipper of trousers \\
23 & Squeezing tooth-paste on a toothbrush \\
\hline & Unwrapping a chocolate bar \\
\hline & Washing one's hands \\
\hline &
\end{tabular}

Items ranked from 1 to 23 are ordered from more difficult to less difficult 
maximum likelihood method was used to determine the significance of each new model.

Boxplots were used to visually display self-perceived manual ability (ABILHAND logits) over time and differences in mean scores between time-points were evaluated by Friedman's two-way analysis of variance by ranks.

Data were analysed with the IBM SPSS Statistics version 25 (IBM Corporation, Armonk, New York, United States). Probability values less than 0.05 were defined as statistically significant. Significance values were adjusted by the Bonferroni correction for multiple tests.

\section{Results}

\section{Participants}

Table 2 presents the demographic and clinical characteristics of the 106 participants and subgroups of mild $(n=$ $41)$, moderate $(n=46)$ and severe stroke $(n=19)$. The mean age of the total group was 68 years (SD 13) and individuals in the subgroup mild were slightly younger. The dominant hand was affected in $43 \%$ of the individuals and the majority (90\%) had lower grip strength in the more affected hand compared to normative values.

The number of participants that completed ABILHAND in the six different time-points varied (Table 3). The main reasons for missing values at early time-points were tiredness and inability to answer the questions adequately (11 and 7 participants at 3 and 10 days, respectively). The drop-out at follow-up time-points was mainly due to decline of the study (16 at 12 months), death (6 at 12 months) and new stroke (7 at 12 months).

\section{Changes of self-perceived manual ability over time}

Analyses of repeated measures showed a significant fixed effect of time on self-perceived manual ability over the first year after stroke in the total group and the subgroups (Table 4 and Table 5). No random effects were found. The mean expected change for the total group over the first year after stroke was 0.26 logits per month from a mean expected baseline logits of 0.46 . The expected increase was 0.22 logits per month in the subgroup of mild stroke severity, 0.31 in the subgroup of moderate stroke severity and 0.24 in in the subgroup of severe stroke severity. Individuals with mild stroke severity had higher expected mean baseline logits (1.72) than individuals with moderate $(0.03)$ and severe strokes $(-1.56)$.

The adjusted model for the total group included a significant fixed effect of time and cofactors age and stroke severity assessed by NIHSS-score (Table 4). In this model the expected increase per month was 0.24 logits during the first year after stroke although this increase was negatively influenced by age $(-0.06$ logit per year)

Table 2 Demographic and clinical characteristics at stroke onset

\begin{tabular}{|c|c|c|c|c|}
\hline & Total group & Mild & Moderate & Severe \\
\hline Individuals per group, n (\%) & $106(100)$ & $41(39)$ & $46(43)$ & $19(18)$ \\
\hline Age, mean years (SD; min-max) & $68(13 ; 26-95)$ & $66(14 ; 26-89)$ & $69(11 ; 38-90$ & $71(14 ; 34-95)$ \\
\hline Gender (male), n (\%) & $61(57.5)$ & $23(56)$ & $25(54)$ & $13(68)$ \\
\hline Living situation (living alone), n (\%) & $41(39)$ & $20(49)$ & $17(37)$ & $4(21)$ \\
\hline Affected arm (right), n (\%) & $46(43)$ & $19(46)$ & $20(44)$ & $7(37)$ \\
\hline Affected side (dominant), n (\%) & $46(43)$ & $18(44)$ & $21(46)$ & $7(37)$ \\
\hline \multicolumn{5}{|l|}{ Stroke type, n (\%) } \\
\hline Ischemic & $88(83)$ & $39(95)$ & $35(76)$ & $14(74)$ \\
\hline Hemorrhagic & $18(17)$ & $2(5)$ & $11(24)$ & $5(26)$ \\
\hline Stroke severity at onset (NIHSS), median (min-max) & $7(0-24)$ & $3(0-4)$ & $8(5-14)$ & $18(15-24)$ \\
\hline Motor function at onset (FMA-UE), median (quartiles) & $34(4-56)$ & $56(47-61)$ & $14(4-41)$ & $4(4-9)$ \\
\hline Sensory function at onset (FMA-UE), median (quartiles) & $11(11-12)$ & $12(11-12)$ & $7(1-12)$ & $0(0-1)$ \\
\hline Grip strength at onset in \% of normative values, mean (SD) & $38(41)$ & $59(35)$ & $28(41)$ & $16(38)$ \\
\hline \multicolumn{5}{|l|}{ Individuals in rehabilitation, $\mathrm{n} / \mathrm{n}$ of time point (\%) } \\
\hline Day 3 & 106/106 (100) & $41 / 41(100)$ & $46 / 46(100)$ & 19/19 (100) \\
\hline Day 10 & $96 / 106(91)$ & $34 / 41(83)$ & $44 / 46(93)$ & $18 / 19(95)$ \\
\hline Week 4 & $80 / 100(80)$ & 23/39 (59) & 40/43 (59) & $17 / 18(94)$ \\
\hline Month 3 & $55 / 90(61)$ & 19/37 (51) & $23 / 39(60)$ & 13/18 (93) \\
\hline Month 6 & $46 / 82(56)$ & $13 / 31(42)$ & $22 / 37(40)$ & $11 / 14(79)$ \\
\hline Month 12 & 29/77 (38) & $6 / 29(21)$ & $14 / 35(40)$ & $9 / 13$ (69) \\
\hline
\end{tabular}

Abbreviations: NIHSS National Institutes of Health Stroke Scale (score range 0-42); Mild < 5 points; Moderate 5-14 points; Severe > 14 points according to the NIHSS; FMA-UE Fugl-Meyer Assessment for Upper Extremity (motor score range 0-66; sensory score range 0-12) 
Table 3 Self-perceived manual ability (ABILHAND logit score) in 6 time-points after stroke

\begin{tabular}{|c|c|c|c|c|c|c|c|}
\hline \multicolumn{2}{|c|}{ Group/subgroup } & \multirow{2}{*}{$\frac{\text { Day } 3}{-0.81}$} & \multirow{2}{*}{$\frac{\text { Day } 10}{0.09}$} & \multirow{2}{*}{$\frac{\text { Week } 4}{1.45}$} & \multirow{2}{*}{$\begin{array}{l}\text { Month } 3 \\
2.57\end{array}$} & \multirow{2}{*}{$\frac{\text { Month } 6}{2.51}$} & \multirow{2}{*}{$\frac{\text { Month } 12}{2.91}$} \\
\hline Total group & Mean & & & & & & \\
\hline & SD & 3.02 & 2.75 & 2.81 & 2.73 & 2.69 & 2.83 \\
\hline & $\mathrm{n}$ & 95 & 99 & 97 & 88 & 82 & 77 \\
\hline \multirow[t]{3}{*}{ Mild } & Mean & 0.41 & 1.54 & 2.84 & 3.51 & 3.44 & 3.80 \\
\hline & SD & 2.79 & 2.13 & 2.19 & 2.46 & 2.40 & 2.34 \\
\hline & $\mathrm{n}$ & 41 & 39 & 39 & 36 & 31 & 30 \\
\hline \multirow[t]{3}{*}{ Moderate } & Mean & -1.09 & -0.39 & 0.78 & 2.34 & 2.35 & 3.10 \\
\hline & SD & 2.57 & 2.53 & 2.79 & 2.69 & 2.68 & 2.49 \\
\hline & $\mathrm{n}$ & 39 & 43 & 43 & 39 & 37 & 34 \\
\hline \multirow[t]{3}{*}{ Severe } & Mean & -3.42 & -1.99 & -0.23 & 0.65 & 0.90 & 0.37 \\
\hline & SD & 3.04 & 2.89 & 2.85 & 2.60 & 2.60 & 3.38 \\
\hline & $\mathrm{n}$ & 15 & 17 & 15 & 13 & 14 & 13 \\
\hline
\end{tabular}

Abbreviations: Mild < 5 points; Moderate 5-14 points; Severe $>14$ points according to the NIHSS

and stroke severity (-0.19 per point in NIHSS-score). Cofactors gender, living condition and affected hand did not influence the model significantly.

The adjusted model for the subgroup with moderate stroke severity (Table 5) included a fixed effect of time (0.28 logits per month) which was negatively adjusted by age (- 0.07 per year). The models for the mild and severe subgroups, in addition to a significant effect of time also included an interaction effect of time and age, i.e. the effect of time varied in different age groups. The interaction effect indicated that the older a person was the lesser was the effect of time.

\section{Changes of self-perceived manual ability between different time-points}

Figure 2 visually displays how self-perceived manual ability (logit score) changes in six time-points over the

Table 4 Effect of time and cofactor age on self-perceived manual ability (ABILHAND logit score) in total group

\begin{tabular}{|c|c|c|}
\hline & Unadjusted model & Adjusted model \\
\hline Parameter & $\begin{array}{l}\text { Estimate } \\
95 \% \mathrm{Cl} \\
\mathrm{p} \text {-value }\end{array}$ & $\begin{array}{l}\text { Estimate } \\
95 \% \mathrm{Cl} \\
p \text {-value }\end{array}$ \\
\hline Intercept & $\begin{array}{l}0.46 \\
0.14 ; 0.79 \\
0.005\end{array}$ & $\begin{array}{l}5.63 \\
3.38 ; 7.88 \\
<0.001\end{array}$ \\
\hline Time (month) & $\begin{array}{l}0.26 \\
0.20 ; 0.32 \\
<0.001\end{array}$ & $\begin{array}{l}0.24 \\
0.21 ; 0.28 \\
<0.001\end{array}$ \\
\hline Age (year) & - & $\begin{array}{l}-0.06 \\
-0.09 ;-0.02 \\
0.001\end{array}$ \\
\hline Stroke severity (NIHSS-score) & - & $\begin{array}{l}-0.19 \\
-0.26 ;-0.12 \\
<0.001\end{array}$ \\
\hline
\end{tabular}

Abbreviations: Cl Confidence interval, NIHSS National Institutes of Health Stroke Scale first year post-stroke for the total group (a) and subgroups (b). Significant increases in the total group were seen between 'Day 3' and all other time-points from 'Week 4' and forward, between 'Day 10 and all timepoints from Week 4' and forward as well as between 'Week 4' and the time-points 'Month 6 and 12' (see Table 6). No significant change was detected beyond 3 months post-stroke.

\section{Discussion}

The current study showed that self-perceived manual ability increased over time the first year after stroke both in the total group and the stroke severity subgroups. The effect of time was modulated both by age and stroke severity in the total group. In the subgroup of moderate stroke severity, similarly to the entire group, age had a significant effect in the model. In the subgroups of mild and severe stroke an interaction effect between time and age was found, which means that the increase in logits was different in different age groups. The interaction effect indicated that the effect of time was reduced in those who were older. Further analyses of change in perceived manual ability between time-points showed that most of the improvements occurred early, predominantly within the first three months after stroke.

Time was the factor that had largest effect on manual ability in the total group and in the subgroups. This is in line with previous research that has shown that time is an independent factor that reflects spontaneous recovery of body functions and activities after stroke [28]. Even though manual ability varied between individuals at baseline in the present study the changes over time were independent from these differences. This has also been found in a previous study where self-perceived manual ability (ABILHAND logits) after a targeted rehabilitation intervention between subacute and chronic phase 
Table 5 Effect of time and cofactor age on self-perceived manual ability (ABILHAND logit score) in three stroke severity subgroups

\begin{tabular}{|c|c|c|c|c|c|c|}
\hline \multirow[t]{3}{*}{ Parameter } & \multicolumn{2}{|l|}{ Mild } & \multicolumn{2}{|l|}{ Moderate } & \multicolumn{2}{|l|}{ Severe } \\
\hline & Unadjusted model & Adjusted model & Unadjusted model & Adjusted model & Unadjusted model & Adjusted model \\
\hline & $\begin{array}{l}\text { Estimate } \\
95 \% \mathrm{Cl} \\
\text { p-value }\end{array}$ & $\begin{array}{l}\text { Estimate } \\
95 \% \mathrm{Cl} \\
\text { p-value }\end{array}$ & $\begin{array}{l}\text { Estimate } \\
95 \% \mathrm{Cl} \\
\text { p-value }\end{array}$ & $\begin{array}{l}\text { Estimate } \\
95 \% \mathrm{Cl} \\
\text { p-value }\end{array}$ & $\begin{array}{l}\text { Estimate } \\
95 \% \mathrm{Cl} \\
\text { p-value }\end{array}$ & $\begin{array}{l}\text { Estimate } \\
95 \% \mathrm{Cl} \\
\text { p-value }\end{array}$ \\
\hline Intercept & $\begin{array}{l}1.72 \\
1.28 ; 2.15 \\
<0.001\end{array}$ & $\begin{array}{l}3.63 \\
0.68 ; 6.57 \\
0.017\end{array}$ & $\begin{array}{l}0.03 \\
-0.43 ; 0.49 \\
0.895\end{array}$ & $\begin{array}{l}4.47 \\
0.44 ; 8.50 \\
0.031\end{array}$ & $\begin{array}{l}-1.56 \\
-2,41 ;-0.71 \\
<0.001\end{array}$ & $\begin{array}{l}0.16 \\
-6.39 ; 6.71 \\
0.960\end{array}$ \\
\hline Time (month) & $\begin{array}{l}0.22 \\
0.14 ; 0.31 \\
<0.001\end{array}$ & $\begin{array}{l}0.62 \\
0.33 ; 0.90 \\
<0.001\end{array}$ & $\begin{array}{l}0.31 \\
0.22 ; 0.40 \\
<0.001\end{array}$ & $\begin{array}{l}0.28 \\
0.22 ; 0.33 \\
<0.001\end{array}$ & $\begin{array}{l}0.24 \\
0.09 ; 0.40 \\
0.003\end{array}$ & $\begin{array}{l}0.75 \\
0.29 ; 1.22 \\
0.002\end{array}$ \\
\hline Age (year) & - & $\begin{array}{l}-0.028 \\
-0.07 ; 0.02 \\
0.197\end{array}$ & - & $\begin{array}{l}-0.066 \\
-0.12 ;-0.01 \\
0.025\end{array}$ & - & $\begin{array}{l}-0.025 \\
-0.12 ; 0.07 \\
0.569\end{array}$ \\
\hline Interaction effect of time and age & - & $\begin{array}{l}-0.006 \\
-0.01 ; 0.00 \\
0.006\end{array}$ & - & - & - & $\begin{array}{l}-0.008 \\
-0.02 ; 0.00 \\
0.018\end{array}$ \\
\hline
\end{tabular}

Abbreviations: Cl Confidence interval, NIHSS National Institutes of Health Stroke Scale, Mild <5 points; Moderate 5-14 points; Severe > 14 points according to the NIHSS

showed same patterns of change over time in subgroups with varying stroke severity [18].

Recovery of the upper extremity body functions and activity capacity after stroke will occur over time and initial severity of motor impairment is an important predictive factor for outcome [28-31]. Changes in impairments during the first weeks after stroke will result in concomitant improvements in activity capacity [32] and recovery over the first months will also be reflected in self-perceived manual ability [33]. However, besides the actual return of manual ability the perception may be affected by other factors such as expectations on recovery and functioning, ability to compensate for disability and adapt to new circumstances after stroke [34]. Previous research has shown that changes in objective and observed measures do not always correspond to self-perceived measures [18, 35, 36]. Measuring both objective, observed and perceived manual ability is therefore important when following recovery of the upper extremity after stroke.

In the adjusted model the effect of time was to a certain degree modulated by stroke severity and age at onset. Accordingly, in older people and in case of more severe stroke the effect of time will be lower compared to younger people and those with less severe stroke. This is in line with previous studies that have found that age and initial stroke severity are important predictive factors for outcome of activities of daily living post-stroke [32, 37, 38]. Stroke severity and age both are associated to increased comorbidity and lower physical and cognitive function $[37,38]$. The results from the current study showed that these factors also had an impact on the perceived manual ability after stroke.

In the current study, several other cofactors were tested in the models. In line with previous research [37], being male or female did not have significant effect on increased perceived manual ability in the current study. Having the dominant arm affected can be considered as a larger disability compared to the non-affected arm. However, having the dominant hand affected did not impact the change in perceived manual ability. A possible explanation could be that, an affected dominant hand would be forced into activities to larger degree than a non-dominant and this might result in larger training dose which might lead to increased regained functioning [39]. ABILHAND is also designed to measure the bimanual ability, which might mask the more subtle differences in hand dominance.

In previous research it has been shown that motor recovery is almost completed after four to 10 weeks [28]. The time course is characterized by larger improvements during the first weeks $[28,29,31,40]$. Also, recovery of body functions will precede the recovery of activities and therefore reach a plateau phase sooner (about two weeks) [32]. As manual activity performance relies on learning new motor processes and compensatory skills and on adaptation to new conditions in daily life, recovery can continue over a longer time. In fact, the current study showed that changes in perceived manual ability improved from stroke onset to one year after stroke. However, most increase in logits was seen early on and after three months the increase levelled out. One reason for this might be due to ceiling effects in ABILHAND in the mild and moderate group. There are some suggestions from previous studies to extend the range of measurement in ABILHAND by adding more difficult items to reduce this ceiling effect $[25,41]$. The rehabilitation interventions are also more concentrated during the first months after stroke, which might influence the perceived manual ability. Interestingly, in rehabilitation 


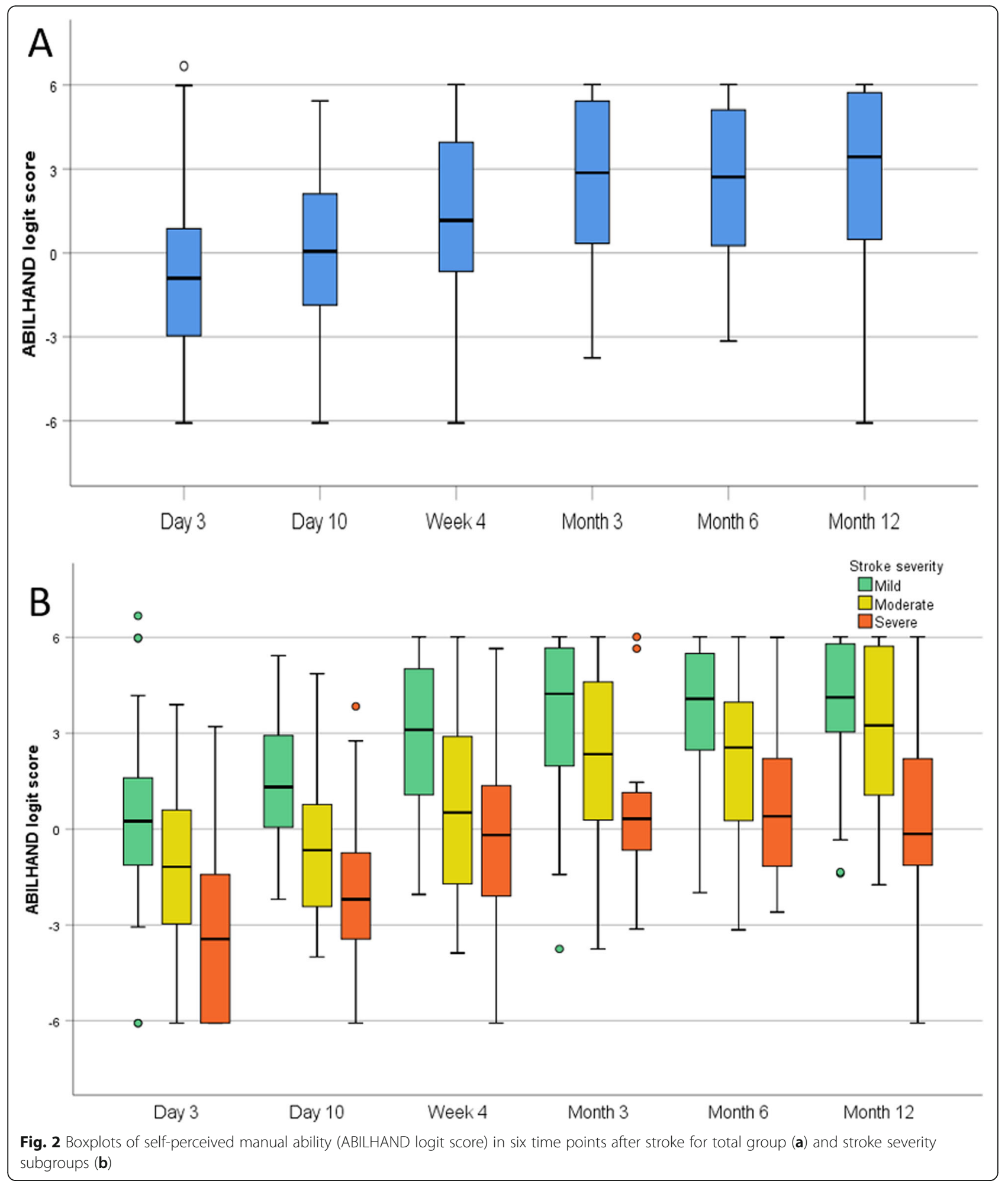

wards individuals tend also to perceive manual ability more positively, in contrast to ordinary daily life circumstances when living at home [18]. When returning home, one might become more aware of the problems in manual activities in real life environments, which might lead to lower ratings. Non-use phenomena and peripheral biomechanical changes of the upper extremity might also have negative effects on manual performance in chronic stages of stroke [10]. 
Table 6 Pairwise comparisons of differences in self-perceived manual ability (ABILHAND logit score) in 6 time points after stroke for total group and subgroups

\begin{tabular}{|c|c|c|c|c|}
\hline Pair of time-points & $\begin{array}{l}\text { Total group } \\
p \text {-value (n) }\end{array}$ & $\begin{array}{l}\text { Mild } \\
p \text {-value (n) }\end{array}$ & $\begin{array}{l}\text { Moderate } \\
p \text {-value (n) }\end{array}$ & $\begin{array}{l}\text { Severe } \\
\mathrm{p} \text {-value (n) }\end{array}$ \\
\hline Day 3 - Day 10 & $0.981(93)$ & $1.000(39)$ & $1.000(39)$ & $1.000(15)$ \\
\hline Day 3 - Week 4 & $<0.001(87)$ & $<0.001$ (39) & $0.015(36)$ & $0.075(12)$ \\
\hline Day 3 - Month 3 & $<0.001(80)$ & $<0.001(36)$ & $<0.001$ (33) & $0.002(11)$ \\
\hline Day 3 - Month 6 & $<0.001(73)$ & $<0.001(31)$ & $<0.001(30)$ & $<0.001(12)$ \\
\hline Day 3 - Month 12 & $<0.001(70)$ & $<0.001(30)$ & $<0.001(30)$ & $0.005(10)$ \\
\hline Day 10 - Week 4 & $<0.001(91)$ & $0.036(37)$ & $0.102(40)$ & $0.959(14)$ \\
\hline Day 10 - Month 3 & $<0.001(83)$ & $<0.001$ (34) & $<0.001(36)$ & $0.075(13)$ \\
\hline Day 10 - Month 6 & $<0.001(78)$ & $<0.001(30)$ & $<0.001$ (34) & $0.012(14)$ \\
\hline Day 10 - Month 12 & $<0.001(73)$ & $<0.001(29)$ & $<0.001(32)$ & $0.128(12)$ \\
\hline Week 4 - Month 3 & $0.122(87)$ & $1.000(36)$ & $0.520(38)$ & $1.000(13)$ \\
\hline Week 4 - Month 6 & $0.005(80)$ & $1.000(31)$ & $0.031(36)$ & $1.000(13)$ \\
\hline Week 4 - Month 12 & $<0.001(75)$ & $0.251(30)$ & $0.001(33)$ & $1.000(12)$ \\
\hline Month 3 - Month 6 & $1.000(78)$ & $1.000(30)$ & $1.000(35)$ & $1.000(13)$ \\
\hline Month 3 - Month 12 & $1.000(73)$ & $1.000(29)$ & $1.000(32)$ & $1.000(12)$ \\
\hline Month 6 - Month 12 & $1.000(74)$ & $1.000(30)$ & $1.000(32)$ & $1.000(12)$ \\
\hline
\end{tabular}

Significant values have been adjusted for the Bonferroni correction for multiple tests

The improvement in perceived manual ability for the subgroup of severe strokes levelled out earlier than in the mild and moderate group. Previous research has found that about $60 \%$ of individuals with severe upper extremity impairment show limited recovery of manual ability [32]. In addition, the recovery after a severe stroke does not follow the same expected pattern as in moderate and mild strokes and the prognosis is less predictable [15]. The present study showed that variations between measurements and between individuals were larger in the group with severe stroke compared to mild and moderate.

Living with the consequences of stroke often means a lifelong adaptation to the disability. In this process, the individual's own perception of difficulties plays a central role, and should guide training and development of strategies to manage meaningful daily activities. Therefore, self-perceived outcome measures are important as they provide information on what matters to the individual that might not always be captured in assessments of function and activity capacity. However, it has been argued that perceived performance in daily activities is difficult to rate early after stroke since the activities have not yet been tried [32]. ABILHAND has, however, the advantage that the logit score is based on the tasks that actually have been performed in real life [11, 27], which makes it an attractive measure to use even early after stroke.

The present study does have some limitations that should be regarded when interpreting the results. Different aspects of functioning e.g. cognitive function, alertness, mood, fatigue and social habits might influence the self-reported outcomes. In the current study, when the participant was not able to adequately answer the questions of the ABILHAND, the test was recorded as missing. Also, patients with comorbidities that possibly could influence the upper extremity functioning were excluded from the study. Nevertheless, other factors, not included in the current study, such as, mild cognitive deficit, general physical function or amount of rehabilitation received might have influenced the results of the self-reported manual ability. The number of participants varied between time-points partly due to limited ability to respond to the questions of the ABILHAND early after stroke, and partly due to the general drop-out from the study over time. However, the mixed model of repeated measurements was chosen as it handles missing values. Even if the sample size in the present study was sufficiently large to evaluate the impact of time and cofactors, subgroups analyses must be interpreted with care. Few significant differences between time-points were found in the subgroup of severe strokes which might have been due to the small sample. Nevertheless, a strength of the current study is the unselected sample which also included severe stroke as this group often is omitted and therefore less investigated in research. This also enhances clinical generalizability of results. Furthermore, well-defined and recommended follow-up time-points after stroke were used [6].

Increased knowledge about changes over time for individuals with stroke and in subgroups of stroke is important and needed. Results from the current study 
contribute to an improved understanding of perceived manual ability during the first year after stroke. Future studies in larger samples could further increase knowledge regarding longitudinal change in different subgroups of stroke severity.

\section{Conclusion}

In conclusion, the present study showed that the selfperceived manual ability increased over the course of the first year after stroke. This increase was however, to some degree influenced negatively by older age and more severe stroke. Most of the improvements in manual ability occurred early, predominantly within the first three months after stroke.

\section{Abbreviations}

NIHSS: National Institutes of Health Stroke Scale; FMA-UE: The Fugl-Meyer Assessment for Upper Extremity; ARAT: Action Research Arm Test;

SALGOT: Stroke Arm Longitudinal Study at the University of Gothenburg

\section{Acknowledgements}

The authors are grateful to the individuals who volunteered to participate and Eva-Lena Bursten for help with data collection and the Riks-Stroke Collaboration for its help with the demographic data.

\section{Authors' contributions}

EE, KSS, HCP, ÅLN and MAM contributed to the design of the study, interpretation of results and drafted/revised the manuscript. All authors have read and approved the final manuscript. In addition to this, MAM and HCP performed the acquisition of data, KSS, HCP and MAM obtained funding and KSS supervised the SALGOT study.

\section{Funding}

The SALGOT-study including this work was supported by following grants: the Swedish state under the agreement between the Swedish government and the country councils (ALF-agreement, ALFGBG 775561); the Swedish Research Council (VR 2012-70X-22122-01-3); The Swedish Heart-Lung Foundation; The Swedish Brain Foundation; Promobilia; and The Swedish Stroke Association. The funding body did not have any role on the design, data collection, analysis, interpretation and drafting of the manuscript.

Open access funding provided by University of Gothenburg.

\section{Availability of data and materials}

Interested researchers may submit requests for data to the authors (contact ks.sunnerhagen@neuro.gu.se). According to the Swedish regulation (http:// www.epn.se/en/start/regulations/), the permission to use data is only for what has been applied for and then approved by the ethical board.

\section{Ethics approval and consent to participate}

The SALGOT-study was approved by the Regional Ethical Review Board in Gothenburg, Sweden (225/08), and each participant or next of kin gave their written informed consent prior their inclusion in the study.

\section{Consent for publication}

Not applicable.

\section{Competing interests}

The authors declare that they have no competing interests.

\section{Author details}

${ }^{1}$ Department of Health Sciences, Lund University, Lund, Sweden. ²Department of Hand Surgery, Skåne University Hospital, Malmö, Sweden. ${ }^{3}$ Department of Clinical Neuroscience, Rehabilitation Medicine, Institute of Neuroscience and Physiology, Sahlgrenska Academy, University of Gothenburg, Per Dubbsgatan 14, 3tr, S-413 45 Göteborg, Sweden.
Received: 23 January 2020 Accepted: 29 April 2020

Published online: 12 May 2020

\section{References}

1. Nakayama H, Jorgensen HS, Raaschou HO, Olsen TS. Recovery of upper extremity function in stroke patients: the Copenhagen stroke study. Arch Phys Med Rehabil. 1994:75:394-8.

2. Persson HC, Parziali M, Danielsson A, Sunnerhagen KS. Outcome and upper extremity function within 72 hours after first occasion of stroke in an unselected population at a stroke unit. A part of the SALGOT study. BMC Neurol. 2012;12:162.

3. Broeks JG, Lankhorst GJ, Rumping K, Prevo AJ. The long-term outcome of arm function after stroke: results of a follow-up study. Disabil Rehabil. 1999; 21:357-64.

4. World Health Organization. International Classification of Functioning, Disability and Health 2001. Available from: http://www.who.int/ classifications/icf/en. Accessed: 26 Nov 2019.

5. Waddell K, Birkenmeier RL, Bland MD, Lang CE. An exploratory analysis of the self-reported goals of individuals with chronic upper-extremity paresis following stroke. Disabil Rehabil. 2016:38:853-7.

6. Kwakkel G, Lannin NA, Borschmann K, English C, Ali M, Churilov L, et al. Standardized measurement of sensorimotor recovery in stroke trials: consensus-based core recommendations from the stroke recovery and rehabilitation roundtable. Int J Stroke. 2017:12:451-61.

7. Brott T, Adams HP Jr, Olinger CP, Marler JR, Barsan WG, Biller J, et al. Measurements of acute cerebral infarction: a clinical examination scale. Stroke. 1989;20:864-70

8. Fugl-Meyer AR, Jaasko L, Leyman I, Olsson S, Steglind S. The post-stroke hemiplegic patient. A method for evaluation of physical performance. Scand J Rehabil Med. 1975;7:13-31.

9. Lyle RC. A performance test for assessment of upper limb function in physical rehabilitation treatment and research. Int J Rehabil Res. 1981;4:48392.

10. Buma F, Kwakkel G, Ramsey N. Understanding upper limb recovery after stroke. Restor Neurol Neurosci. 2013:31:707-22.

11. Penta M, Tesio L, Arnould C, Zancan A, Thonnard JL. The ABILHAND questionnaire as a measure of manual ability in chronic stroke patients: Rasch-based validation and relationship to upper limb impairment. Stroke. 2001;32:1627-34.

12. Stewart JC, Cramer SC. Patient-reported measures provide unique insights into motor function after stroke. Stroke. 2013:44:1111-6.

13. Ward NS. Restoring brain function after stroke - bridging the gap between animals and humans. Nat Rev Neurol. 2017;13:244-55.

14. Winters C, Kwakkel G, van Wegen EEH, Nijland RHM, Veerbeek JM, Meskers CGM. Moving stroke rehabilitation forward: the need to change research. NeuroRehabil. 2018;43:19-30.

15. Winters C, van Wegen EE, Daffertshofer A, Kwakkel G. Generalizability of the proportional recovery model for the upper extremity after an ischemic stroke. Neurorehabil Neural Repair. 2015;29:614-22.

16. Kristersson T, Persson HC, Alt MM. Evaluation of a short assessment for upper extremity activity capacity early after stroke. J Rehabil Med. 2019;51: 257-63.

17. Rand D, Eng JJ. Predicting daily use of the affected upper extremity 1 year after stroke. J Stroke Cerebrovasc. 2015:24:274-83.

18. Franck JA, Smeets R, Seelen HAM. Changes in arm-hand function and armhand skill performance in patients after stroke during and after rehabilitation. PLoS One. 2017;12:e0179453.

19. Alt Murphy M, Persson HC, Danielsson A, Broeren J, Lundgren-Nilsson A, Sunnerhagen KS. SALGOT - Stroke Arm Longitudinal study at the University of Gothenburg, prospective cohort study protocol. BMC Neurol. 2011;11:56.

20. Nationella riktlinjer för strokesjukvård 2018 (National stroke guidelines 2018). Stockholm: Socialstyrelsen (national board of health and welfare); 2018 Available from: https:/wwwsocialstyrelsense/globalassets/sharepoint-dokument/ artikelkatalog/nationella-riktlinjer/2018-3-11pdf Accessed: 26 Nov 2019.

21. Appelros $P$, Terent A. Characteristics of the National Institute of health stroke scale: results from a population-based stroke cohort at baseline and after one year. Cerebrovasc Dis. 2004;17:21-7.

22. Denvall V, Elmstahl S, Prigatano GP. Replication and construct validation of the Barrow neurological institute screen for higher cerebral function with a Swedish population. J Rehabil Med. 2002;34:153-7. 
23. Mathiowetz V, Kashman N, Volland G, Weber K, Dowe M, Rogers S. Grip and pinch strength: normative data for adults. Arch Phys Med Rehabil. 1985;66: 69-74.

24. Mathiowetz V, Weber K, Volland G, Kashman N. Reliability and validity of grip and pinch strength evaluations. J Hand Surg Am. 1984;9:222-6.

25. Ekstrand E, Lindgren I, Lexell J, Brogardh C. Test-retest reliability of the ABILHAND questionnaire in persons with chronic stroke. PM R. 2014;6:32431.

26. Alt Murphy M, Resteghini C, Feys P, Lamers I. An overview of systematic reviews on upper extremity outcome measures after stroke. BMC Neurol. 2015;15:29.

27. Rasch G. Probabilistic models for some intelligence and attainment tests. Expanded ed. Chicago: University of Chicago Press; 1980

28. Kwakkel G, Kollen B, Twisk J. Impact of time on improvement of outcome after stroke. Stroke. 2006:37:2348-53.

29. Kwakkel G, Kollen B. Predicting improvement in the upper paretic limb after stroke: a longitudinal prospective study. Restor Neurol Neurosci. 2007;25: 453-60.

30. Coupar F, Pollock A, Rowe P, Weir C, Langhorne P. Predictors of upper limb recovery after stroke: a systematic review and meta-analysis. Clin Rehabil. 2012;26:291-313.

31. Kwakkel G, Kollen BJ, van der Grond J, Prevo AJ. Probability of regaining dexterity in the flaccid upper limb: impact of severity of paresis and time since onset in acute stroke. Stroke. 2003;34:2181-6.

32. Kwakkel G, Kollen BJ. Predicting activities after stroke: what is clinically relevant? Int J Stroke. 2013;8:25-32

33. Beebe JA, Lang CE. Relationships and responsiveness of six upper extremity function tests during the first six months of recovery after stroke. J Neurol Phys Ther. 2009;33:96-103

34. Barclay-Goddard R, Epstein JD, Mayo NE. Response shift: a brief overview and proposed research priorities. Qual Life Res. 2009;18:335-46.

35. van Delden AL, Peper CL, Beek PJ, Kwakkel G. Match and mismatch between objective and subjective improvements in upper limb function after stroke. Disabil Rehabil. 2013;35:1961-7.

36. Essers B, Meyer S, De Bruyn N, Van Gils A, Boccuni L, Tedesco Triccas L, et al. Mismatch between observed and perceived upper limb function: an eyecatching phenomenon after stroke. Disabil Rehabil. 2019:41:1545-51.

37. Veerbeek JM, Kwakkel G, van Wegen EE, Ket JC, Heymans MW. Early prediction of outcome of activities of daily living after stroke: a systematic review. Stroke. 2011;42:1482-8.

38. Meyer MJ, Pereira S, McClure A, Teasell R, Thind A, Koval J, et al. A systematic review of studies reporting multivariable models to predict functional outcomes after post-stroke inpatient rehabilitation. Disabil Rehabil. 2015:37:1316-23.

39. Harris JE, Eng JJ. Individuals with the dominant hand affected following stroke demonstrate less impairment than those with the nondominant hand affected. Neurorehabil Neural Repair. 2006;20:380-9.

40. Winters C, Kwakkel G, Nijland R, van Wegen E. Consortium EX-s. when does return of voluntary finger extension occur post-stroke? A prospective cohort study. PLoS One. 2016;11:e0160528.

41. Barrett LE, Cano SJ, Zajicek JP, Hobart, JC. Can the ABILHAND handle manual ability in MS? Mult Scler. 2013;19:806-15.

\section{Publisher's Note}

Springer Nature remains neutral with regard to jurisdictional claims in published maps and institutional affiliations.

Ready to submit your research? Choose BMC and benefit from:

- fast, convenient online submission

- thorough peer review by experienced researchers in your field

- rapid publication on acceptance

- support for research data, including large and complex data types

- gold Open Access which fosters wider collaboration and increased citations

- maximum visibility for your research: over $100 \mathrm{M}$ website views per year

At BMC, research is always in progress.

Learn more biomedcentral.com/submissions 